\title{
BALANÇO HÍDRICO NO SOLO PARA PORTA-ENXERTOS DE CITROS EM ECOSSISTEMA DE TABULEIRO COSTEIRO
}

\author{
Fernando Luis Dultra Cintra ${ }^{1}$, Paulo Leonel Libardi ${ }^{2}$ \& Antonio Melhem Saad ${ }^{3}$
}

\begin{abstract}
RESUMO
A má distribuição das chuvas e a existência de camadas coesas em muitos solos dos tabuleiros promovem, muitas vezes, alterações importantes no regime hídrico do solo e nas taxas de evapotranspiração das culturas exploradas nesse ecossistema. Objetivou-se, com este trabalho, conhecer, através do balanço hídrico, como esses processos ocorrem e, também, contribuir para o estabelecimento de práticas de manejo visando ao melhor uso das reservas de água no solo. Todos os componentes do balanço foram medidos, à exceção da evapotranspiração, que foi calculada. Os resultados obtidos permitiram concluir que a maior demanda hídrica da laranjeira aconteceu nos meses de outubro e novembro e que, com base na taxa de evapotranspiração, a Tangerina Cleópatra (Citrus reshni Hort. ex Tan.) foi o porta-enxerto menos adaptado e o Limão Cravo (Citrus limonia Osbeck) o que apresentou as melhores características de adaptação à área estudada.
\end{abstract}

Palavras-chave: balanço hídrico, citros, porta-enxerto, tabuleiro costeiro

\section{WATER BALANCE IN SOIL FOR CITRUS ROOTSTOCKS IN THE BRAZILIAN COASTAL TABLELAND ECOSYSTEM}

\begin{abstract}
The irregular rain distribution and the existence of hardened layers in several soils of the tablelands promote, sometimes, important changes in the soil water regime and in the rates of evapotranspiration of the crops utilized in that ecosystem. The objective of this work was to know, by means of the water balance, how these processes occur in the studied area and to contribute to the establishment of management practices in order to make better use of the soil water. All components of the equations were measured, with exception of the evapotranspiration which was calculated. According to the results, it could be concluded that the orange tree had the maximum water consumption during the months of October and November and that, in terms of the rootstocks during these periods of great water consumption, the "Tangerina Cleópatra" (Citrus reshni Hort. former Tan.) was the less adapted and the "Limão Cravo" (Citrus limonia Osbeck) presented the best adaptation characteristics to the studied area.
\end{abstract}

Key words: water balance, citrus, rootstock, coastal tablelands

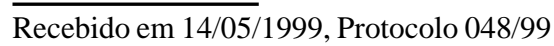

${ }_{1}^{1}$ Pesquisador da Embrapa Tabuleiros Costeiros, Av. Beira Mar 3250, CEP 49025 - 040, Aracaju, SE. E-mail: fcintra@ cpatc.embrapa.br

${ }^{2}$ Professor da ESALQ/USP, Av. Pádua Dias 11, CEP 13418 - 900, Piracicaba, SP. Fone: (0xx19) 422 5925, Fax: (0xx19) 4345259.

E-mail: pllibard@mandi.esalq.usp.br

${ }^{3}$ Pesquisador colaborador do IPT-Digeo, Pós-doutorando na ESALQ/USP. E-mail: amsaad@ carpa.ciagri.usp.br 


\section{INTRODUÇÃO}

Os baixos platôs costeiros, também denominados tabuleiros costeiros, são superfícies relacionadas aos sedimentos do Grupo Barreiras-Terciário Superior. Segundo dados constantes do plano diretor da Embrapa Tabuleiros Costeiros (1994) essas áreas, que correspondem a aproximadamente 8,5 milhões de hectares, contribuem, respectivamente, com 26,4 e $38 \%$ do PIB gerado pelas culturas temporárias e permanentes dos Estados da Bahia, Sergipe, Alagoas, Pernambuco, Paraíba, Rio Grande do Norte e Ceará. Embora reconhecidas a importância e a existência de grande mercado potencial e de demanda reprimida por produtos agrícolas, a atividade agropecuária tem sido, via de regra, inviabilizada pelas baixas produções e alta relação custo/benefício proporcionada pelas culturas.

O meio físico, representado principalmente pelos horizontes coesos e o clima, pela má distribuição das chuvas, as quais se concentram, em torno de $80 \%$, entre os meses de abril e setembro, são alguns dos fatores responsáveis pela baixa produtividade das espécies cultivadas nos tabuleiros costeiros. Entre seus efeitos mais importantes encontram-se as alterações no potencial mátrico da água no solo, na aeração do solo, na temperatura e na resistência do solo à penetração de raízes, vitais para o crescimento e desenvolvimento das espécies vegetais.

A fruticultura tem sido uma das principais opções de atividade agrícola no ecossistema dos tabuleiros costeiros do Nordeste em virtude, principalmente, da topografia predominantemente plana dos solos, da expansão da indústria de sucos no País e do regime climático que, em certos aspectos, contribui para o bom desenvolvimento dessa atividade na região. Embora com essas características, em muitas áreas dos tabuleiros do norte do Estado da Bahia e em todo o Estado de Sergipe, a citricultura não tem sido bem sucedida obtendo-se, muitas vezes, produtividades incompatíveis com os investimentos aplicados.

Segundo Reuther (1973) os estudos relacionados com a influência do ambiente sobre a cultura de citros devem ser direcionados principalmente para avaliação dos efeitos dos fatores climáticos sobre a transpiração e uso de água pelas plantas e sobre o regime hídrico do solo, em virtude da forte relação entre disponibilidade de água no solo com a produtividade, vigor das plantas e qualidade dos frutos. Esta é, também, a posição de Oliveira (1991) o qual acrescenta que, por ser o citros uma espécie perenifólia, requer níveis contínuos de umidade no solo, além de condições adequadas de drenagem, porosidade e permeabilidade. Da mesma forma, Ortolani et al. (1991) afirmam que as necessidades hídricas dos citros variam em função da distribuição espacial e temporal das condições climáticas, dos fatores relacionados ao manejo do pomar, da combinação enxerto/porta-enxerto e das características hídricas do solo.

O conhecimento de como as plantas utilizam a água no solo e de como respondem aos níveis de armazenagem a partir do balanço hídrico, pode ser uma saída viável para o estabelecimento de estratégias eficazes de manejo visando ao melhor uso possível das reservas de água no solo pelas culturas. O movimento cíclico da água na lavoura começa com a sua penetração no solo por meio da infiltração, continua com seu armazenamento temporário na zona do sistema radicular e termina com sua remoção do solo por meio da drenagem, da evaporação e da absorção pelas raízes (Hillel, 1970). O que é feito através do balanço hídrico nada mais é do que se tentar quantificar essas entradas e saídas de água no sistema solo-planta.

Para se efetuar o balanço hídrico de uma cultura é necessário, portanto, computar as entradas de água no solo via precipitação pluvial ou irrigação, a partir da sua infiltração na superfície, e as saídas, representadas pela drenagem interna, evapotranspiração e deflúvio superficial num volume de solo, com base na configuração do sistema radicular da cultura em estudo, em determinado período de tempo; se a quantidade de água que entra no tempo considerado for maior que a quantidade que sai durante o mesmo período, o saldo será positivo e, caso contrário, será negativo. Tanto o saldo positivo como o negativo serão medidos pela variação de armazenagem de água no perfil do solo no período considerado (Libardi, 1995).

A importância do balanço hídrico como ferramenta para avaliar a intensidade das saídas e entradas de água no solo e, por conseguinte, para definição dos períodos mais prováveis de déficit hídrico para a cultura, está relacionada não só ao conhecimento dos fatores que o compõem (evapotranspiração, precipitação, drenagem interna ou ascensão capilar) como, também, ao conhecimento das características da planta, principalmente da sua fenologia, que representa o ponto de partida para a interpretação coerente dos resultados do balanço. Com a realização deste trabalho objetivou-se produzir informações úteis ao estabelecimento de práticas de manejo para a cultura dos citros, capazes de minimizar os problemas causados pelas camadas coesas e seus efeitos na dinâmica da água no solo, em uma classe de solo representativa dos tabuleiros costeiros.

\section{MATERIAL E MÉTODOS}

O experimento foi conduzido no Campo Experimental de Umbaúba, da Embrapa Tabuleiros Costeiros, no ano de 1995, cujas coordenadas geográficas são $11^{\circ} 22^{\prime} 37^{\prime \prime}$ de latitude sul, 3740'26" de longitude oeste e altitude média de 109 m. A estação experimental situa-se na região Tabuleiro Sul do Estado de Sergipe, da qual fazem parte, também, os municípios de Salgado, Boquim, Pedrinhas, Arauá, Santa Luzia do Itanhy, Indiaroba e Cristinápolis os quais, junto com Umbaúba, representam o principal pólo de produção de citros do Estado. Na Tabela 1 são apresentados os dados meteorológicos (disponíveis) em uma série de onze anos, na qual é possível observar que os valores médios para temperatura, umidade relativa do ar e precipitação pluvial neste período foram de, respectivamente, $24^{\circ} \mathrm{C}, 81 \%$ e $1318 \mathrm{~mm}$.

As avaliações foram realizadas em uma quadra experimental implantada em 1984, no delineamento de blocos ao acaso, com cinco repetições, quatro plantas por parcela e espaçamento entre plantas de 7 × 3,5 m, para observação do comportamento de cinco porta-enxertos de citros ao ecossistema de tabuleiro costeiro. A copa utilizada foi Laranja Pêra (Citrus sinensis (L.) Osbeck) em combinação com os porta-enxertos: Limão Volcameriano Palermo e Catânia (Citrus volkameriana Pasquale), Limão Cravo (Citrus limonia Osbeck), Limão Rugoso da Flórida (Citrus jambhiri Lush) e Tangerina Cleópatra (Citrus reshni Hort. ex Tan ) segundo classificação de T. Tanaka (Castle et al. 1989). 
Tabela 1. Dados climáticos da área estudada, série de onze anos entre 1974 e 1987

\begin{tabular}{cccccc}
\hline \multirow{2}{*}{ Anos } & \multicolumn{3}{c}{ Temperatura Média do Ar } \\
& \multicolumn{3}{c}{$\left({ }^{\circ} \mathrm{C}\right)$} & $\begin{array}{c}\text { Umidade } \\
\text { Relativa }\end{array}$ & $\begin{array}{c}\text { Precipitação } \\
\text { Pluvial } \\
(\%)\end{array}$ \\
\cline { 2 - 4 }$($ Máxima & Mínima & Média & $(\mathrm{mm})$ \\
\hline 1974 & 29,0 & 21,5 & 23,9 & 83,4 & 1519,8 \\
1975 & 29,0 & 19,8 & 23,7 & 82,2 & 1759,6 \\
1976 & 28,8 & 19,0 & 23,5 & 81,0 & 1115,3 \\
1977 & 28,5 & 19,6 & 23,5 & 83,4 & 1562,5 \\
1979 & 29,5 & 20,9 & 24,1 & 81,9 & 1288,4 \\
1981 & 28,7 & 20,4 & 23,8 & 81,1 & 1043,9 \\
1982 & 29,1 & 20,8 & 24,3 & 80,9 & 1283,4 \\
1983 & 29,9 & 21,0 & 24,7 & 79,3 & 989,6 \\
1984 & 29,1 & 20,9 & 24,6 & 80,4 & 1298,4 \\
1986 & 28,7 & 20,1 & 23,9 & 82,2 & 1636,8 \\
1987 & 30,1 & 20,3 & 24,7 & 79,7 & 999,7 \\
\hline Média & 29,1 & 20,4 & 24,1 & 81,4 & 1317,9 \\
\hline
\end{tabular}

Para identificação da classe de solo da área experimental foi aberta trincheira para classificação e descrição morfológica do perfil, além da coleta de amostras, por horizonte, para caracterização física e química. O perfil do solo, classificado como Podzólico Acinzentado na classificação brasileira e como Aquic Kandiustalf na americana, foi subdividido em cinco horizontes (Ap - 0 a 0,2 m, BA - 0,2 a 0,4 m, Bt - 0,42 a 0,85,

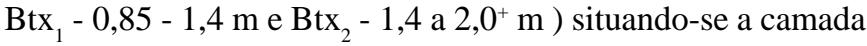
coesa entre o horizonte de transição BA e o Btx ${ }_{1}$. Quanto às características físicas, podem ser observados, na Tabela 2 e por horizonte, os resultados de granulometria e das densidades do solo e das partículas.

Os parâmetros hídricos constaram da curva de retenção de água no solo, feita a partir de amostras de solo inalteradas coletadas com aparelho de Uhland e composta pelas tensões de $0,1,4,7,10,30,80,100,500$ e $1500 \mathrm{kPa}$, condutividade hidráulica, determinada pelo método do perfil instantâneo, e avaliação dos potenciais mátricos no campo, utilizando-se um conjunto de oito tensiômetros com manômetro de mercúrio, situado a, aproximadamente, 2,5 $\mathrm{m}$ do tronco de cada um dos porta-enxertos avaliados e instalados nas profundidades de $0,1,0,3,0,5,0,7$, $0,9,1,1,1,3$ e $1,5 \mathrm{~m}$.

\section{Componentes do balanço hídrico}

O balanço hídrico no solo onde se encontravam os portaenxertos, foi estimado com base no princípio da conservação das massas o qual pode ser representado pela relação matemática das entradas e saídas de água em determinado volume de solo e descrito pela equação:

$$
\Delta \mathrm{h}=\mathrm{P} \pm \mathrm{D}-\mathrm{ET}
$$

em que $\Delta \mathrm{h}$ corresponde à variação de armazenagem de água no perfil do solo durante o período considerado $\Delta \mathrm{t}$ da camada 0 - L m, P à precipitação pluvial em $\Delta \mathrm{t}, \mathrm{D}$ à drenagem interna ou ascensão capilar em $\Delta \mathrm{t}$, na profundidade $\mathrm{L}$ e ET à evapotranspiração em $\Delta \mathrm{t}$. Como o parâmetro $\mathrm{D}$ pode constituir-se em entrada ou saída de água, a sua representação matemática é feita com ambos os sinais, positivo e negativo. Todos os componentes da equação foram medidos, à exceção da evapotranspiração, a qual foi calculada explicitando-a da Eq. 1, como representado a seguir:

$$
\mathrm{ET}=\Delta \mathrm{h}-\mathrm{P} \pm \mathrm{D}
$$

Os parâmetros I (irrigação) e R (deflúvio superficial) que, normalmente, fazem parte da equação do balanço hídrico, não foram considerados neste trabalho em virtude da experimentação ter sido realizada sob condições de sequeiro e em solo praticamente plano, onde o deflúvio foi considerado nulo.

A profundidade $\mathrm{L}$ considerada foi de $1,1 \mathrm{~m}$ e os intervalos de tempo, segmentados do período total de um ano de acompanhamento, para todos os cinco porta-enxertos, foram: 01/12/95 a 25/03/96 (1), 26/03 a 15/04 (2), 16/04 a 15/05 (3), 16/05 a 10/06 (4), 11/06 a 30/06 (5), 01/07 a 31/07 (6), 01/08 a 31/08 (7), 01/09 a 30/09 (8), 01/10 a 31/10 (9) e 01/11 a 30/11 (10). Os intervalos de tempo $1,2,9$ e 10 corresponderam à estação seca e os intervalos 3, 4, 5, 6, 7 e 8 à estação chuvosa.

A precipitação pluvial foi medida com pluviômetro e o fluxo de água (q), que drena (drenagem interna, - D) ou ascende (ascensão capilar, +D) ao volume de solo considerado, foi medido com base na equação da Darcy-Buckingham:

$$
q=-K(\theta) \operatorname{Grad} \phi_{t}
$$

em que $K(\theta)$ é a condutividade hidráulica do solo não saturado $\left(\mathrm{m} \operatorname{dia}^{-1}\right)$ função da umidade do solo $(\theta)$ e que expressa a facilidade com que a água é transportada, e gràd $\phi_{t}$ é o gradiente de potencial total. $\mathrm{O}$ gradiente foi obtido pela diferença do potencial total $\left(\phi_{t}\right)$ entre os pontos 0,9 e $1,3 \mathrm{~m}$ dividido pela distância $(\Delta \mathrm{z})$ entre eles $(0,4 \mathrm{~m})$ :

$$
\operatorname{Grad} \phi_{\mathrm{t}}=\frac{\phi_{\mathrm{t}(0,9 \mathrm{~m})}-\phi_{\mathrm{t}(1,3 \mathrm{~m})}}{\Delta \mathrm{z}_{(0,4 \mathrm{~m})}}
$$

\begin{tabular}{|c|c|c|c|c|c|c|c|c|c|c|c|}
\hline \multirow[b]{2}{*}{ Horiz. } & \multirow{2}{*}{$\begin{array}{c}\text { Prof. } \\
\text { (m) }\end{array}$} & \multicolumn{5}{|c|}{ Frações de Areia* } & \multirow{2}{*}{$\begin{array}{l}\text { Areia } \\
\text { Total }\end{array}$} & \multirow{2}{*}{ Silte } & \multirow{2}{*}{ Argila } & \multirow{2}{*}{$\begin{array}{c}\text { Densidade } \\
\text { do Solo } \\
\mathrm{kg} \mathrm{dm}^{-3}\end{array}$} & \multirow{2}{*}{$\begin{array}{c}\text { Porosidade } \\
\text { Total } \\
\%\end{array}$} \\
\hline & & AMG & $\mathrm{AG}$ & $\mathrm{AM}$ & $\begin{array}{c}\mathrm{AF} \\
\mathrm{g}\end{array}$ & $\mathrm{AMF}$ & & & & & \\
\hline $\mathrm{Ap}$ & $0,00-0,20$ & 37,0 & 200,4 & 303,0 & $\begin{array}{r}8 \\
196,6\end{array}$ & 61,5 & 798,6 & 60,9 & 140,5 & 1,5 & 40,9 \\
\hline BA & $0,20-0,42$ & 26,4 & 155,30 & 249,0 & 173,6 & 63,9 & 668,2 & 65,2 & 266,5 & 1,7 & 33,9 \\
\hline $\mathrm{Bt}$ & $0,42-0,85$ & 29,3 & 130,1 & 196,7 & 147,8 & 63,5 & 567,5 & 79,7 & 352,7 & 1,6 & 36,7 \\
\hline Btx1 & $0,85-1,40$ & 19,3 & 105,3 & 170,7 & 130,6 & 71,2 & 497,1 & 153,8 & 349,1 & 1,5 & 39,1 \\
\hline Btx2 & $1,40-2,00^{+}$ & 22,50 & 94,2 & 153,3 & 130,6 & 75,8 & 476,4 & 203,8 & 319,7 & 1,5 & 40,0 \\
\hline
\end{tabular}

Tabela 2. Características física de diferentes horizontes do solo 
A variação de armazenagem $\Delta \mathrm{h}$ foi determinada pela diferença dos valores de umidade obtidos no perfil (de $\bar{\theta} 0$ a L, sendo $\mathrm{L}$ igual a $1,1 \mathrm{~m}$ ) nos tempos final e inicial de cada período considerado, expressa pela equação:

$$
\Delta \mathrm{h}=\left[\bar{\theta}_{(\mathrm{f})}-\bar{\theta}_{(\mathrm{i})}\right] \mathrm{L}
$$

O índice eficiência do uso da água (EUA) utilizado para interpretação dos dados, foi calculado com base em Hillel (1972) e obtido através da relação entre o rendimento da laranja Pêra nas diferentes combinações com os porta-enxertos avaliados, e a taxa de evapotranspiração anual, expresso pela equação:

$$
\mathrm{EUA}=\frac{\mathrm{y}_{\mathrm{w}}}{\mathrm{ET}_{\mathrm{a}}}
$$

em que $\mathrm{y}_{\mathrm{w}}$ corresponde ao rendimento obtido em $\mathrm{kg} \mathrm{ha}^{-1} \mathrm{ano}^{-1} \mathrm{e}$ $\mathrm{ET}_{\mathrm{a}}$ à evapotranspiração anual, calculada pelo método do balanço hídrico na camada 0,0 a 1,1m, em mm de água.

\section{RESULTADOS E DISCUSSÃO}

Na Tabela 3 estão apresentados os resultados do balanço hídrico realizado para a camada de solo de 0 a $1,1 \mathrm{~m}$ de profundidade, para cada porta-enxerto, em dez períodos ao longo de um ano de monitoramento do potencial mátrico da água no solo (dezembro de 1995 a novembro de 1996). Nessa tabela é possível se observar que o porta-enxerto Limão Cravo manteve uma taxa anual de evapotranspiração de 757 contra $945 \mathrm{~mm}$ da Tangerina Cleópatra, o que representa uma diferença em torno de $200 \mathrm{~mm}$ anuais de água evapotranspirada entre os dois materiais. Quanto aos outros porta-enxertos, os Limões Volcamerianos apresentaram taxas similares e próximo à do Limão Cravo, enquanto a taxa do Limão Rugoso esteve mais próximo da Tangerina Cleópatra. Com base nesses dados é possível se inferir que os dois últimos porta-enxertos devem sofrer maior nível de estresse nos períodos de déficit hídrico ou de maior demanda por água.

Esses resultados combinam com as observações de Mechlia \& Carroll (1989) os quais estimaram, por modelagem, o intervalo de evapotranspiração entre 4 e $8 \mathrm{~mm} \mathrm{dia}^{-1}$ como limitante à produção de citros. Na Tabela 3 verifica-se que os valores máximos de evapotranspiração diária nos períodos de maior demanda hídrica (época de emissão dos botões florais, entre os meses de agosto e novembro) são observados na Tangerina Cleópatra e os menores valores no Limão Cravo, os quais estão abaixo ou muito próximo do limite mínimo estabelecido por esses autores. As informações existentes para as regiões produtoras de citros do Nordeste indicam, como período de maior demanda de água, os meses de agosto a novembro, quando as plantas iniciam a emissão dos botões florais, a frutificação e o desenvolvimento dos frutos e, como período de menor demanda, os meses de abril a setembro, quando ocorrem o início da maturação e a colheita dos frutos.

Nas Figura 1 onde os componentes do balanço (precipitação, evapotranspiração, drenagem ou ascensão capilar) para diferentes porta-enxertos são visualizados em conjunto, é possível avaliar-se o comportamento da água no solo (drenagem e ascensão capilar) e na planta (evapotranspiração) em função da distribuição das chuvas ao longo de um ano de observação. Vale lembrar que, na análise da figura, deve-se estar atento para o fato de que o primeiro período tem duração de 116 dias (Tabela 3) e, portanto, deve ser excluído da comparação com os demais, devido à grande dessemelhança quanto ao intervalo de tempo.

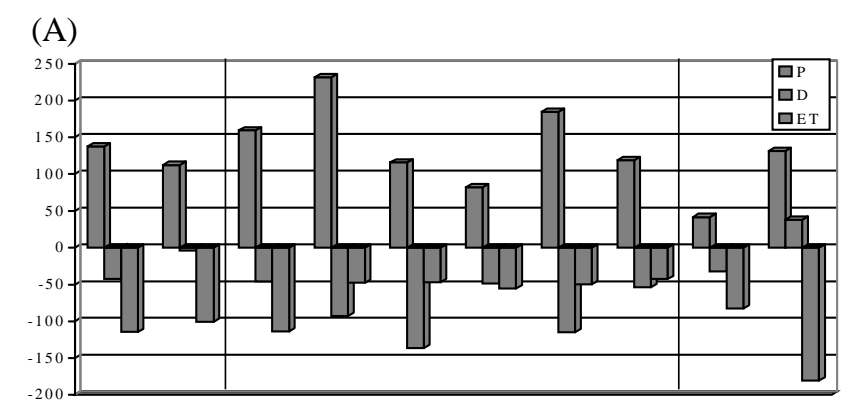

(B)

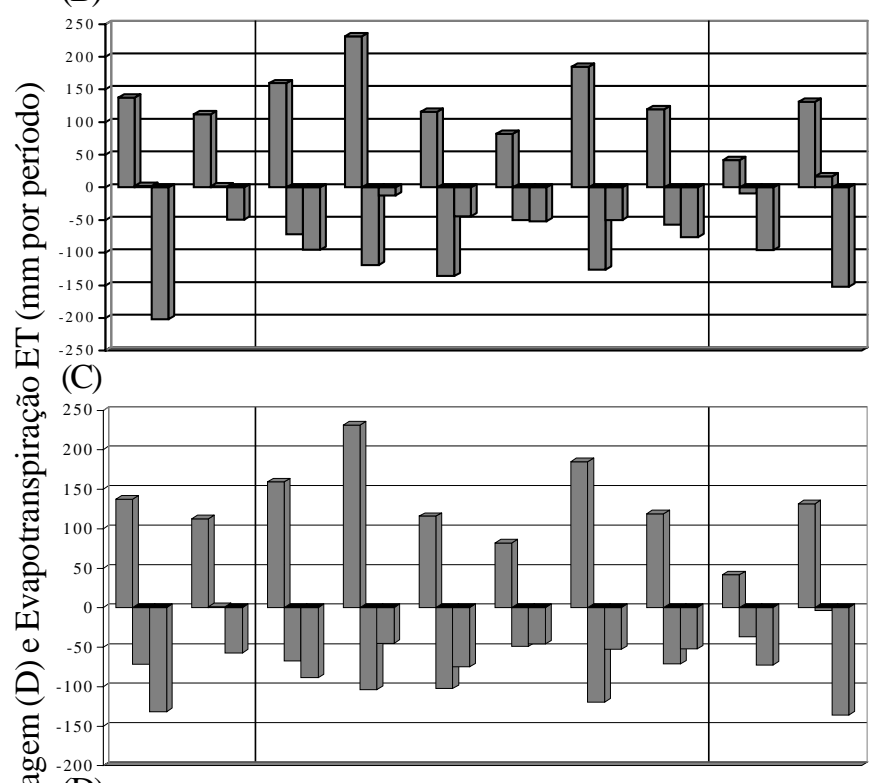

(D)

(2)

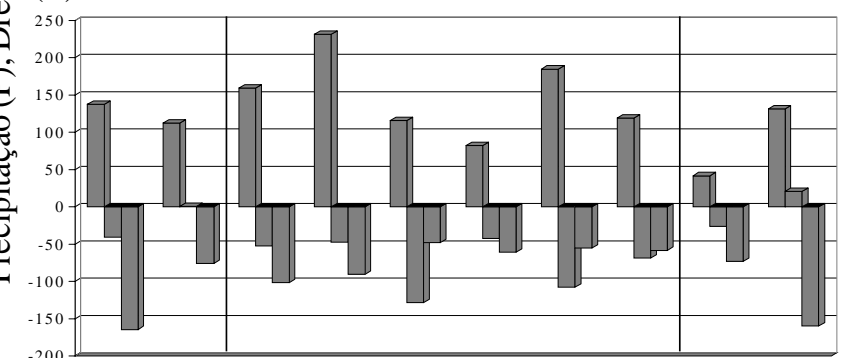

$(\mathrm{E})$

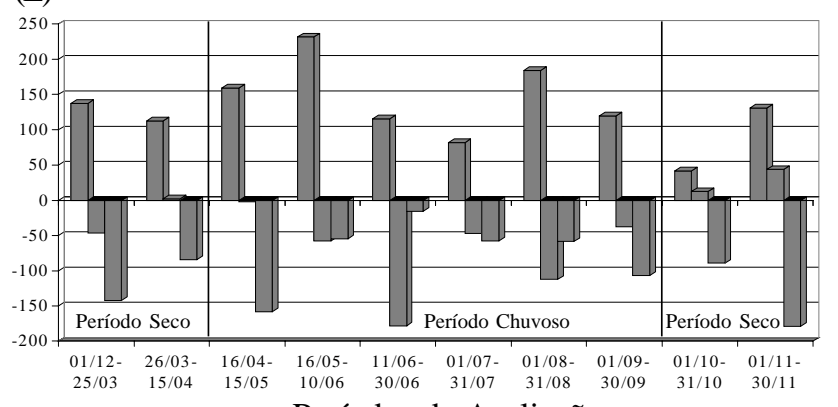

Períodos de Avaliação

Figura 1. Balanço hídrico dos porta-enxertos: Limão Volcameriano Palermo (A), Limão Volcameriano Catânia (B), Limão Cravo (C), Limão Rugoso da Flórida (D) e Tangerina Cleópatra (E) 
Tabela 3. Balanço hídrico do solo para todos os porta-enxertos estudados

\begin{tabular}{|c|c|c|c|c|c|c|c|c|}
\hline \multirow[t]{2}{*}{ Porta-enxertos } & \multirow{2}{*}{$\begin{array}{c}\text { Período de } \\
\text { Balanço }\end{array}$} & \multirow{2}{*}{$\begin{array}{l}\mathrm{N}^{\mathrm{o}} \mathrm{de} \\
\text { Dias }\end{array}$} & $\mathrm{P}$ & $\mathrm{D}$ & $\begin{array}{c}\text { Variação de } \\
\text { Armaz. }\end{array}$ & $\begin{array}{c}\text { ET } \\
\text { (período) }\end{array}$ & \multirow{2}{*}{$\begin{array}{l}\text { ET (diária) } \\
\left(\mathrm{mm} \mathrm{dia}^{-1}\right)\end{array}$} & \multirow{2}{*}{$\begin{array}{c}\text { EUA } \\
\left(\mathrm{kg} \mathrm{m}^{-3}\right)\end{array}$} \\
\hline & & & & & n) & & & \\
\hline \multirow[t]{11}{*}{ Limão V. Palermo } & $01 / 12-25 / 03$ & 116 & 137,7 & $-42,7$ & $-19,5$ & $-114,5$ & $-1,0$ & \\
\hline & $26 / 03-15 / 04$ & 21 & 112,4 & $-4,1$ & 7,6 & $-100,7$ & $-4,8$ & \\
\hline & $16 / 04-15 / 05$ & 30 & 159,4 & $-45,7$ & 0,1 & $-113,6$ & $-3,8$ & \\
\hline & 16/05-10/06 & 26 & 231,6 & $-92,8$ & 91,0 & $-47,8$ & $-1,8$ & \\
\hline & $11 / 06-30 / 06$ & 20 & 115,8 & $-136,3$ & $-67,5$ & $-47,0$ & $-2,4$ & \\
\hline & 01/07-31/07 & 31 & 82,2 & $-48,7$ & $-21,6$ & $-55,1$ & $-1,8$ & \\
\hline & 01/08-31/08 & 31 & 184,6 & $-114,8$ & 20,0 & $-49,8$ & $-1,6$ & \\
\hline & 01/09-30/09 & 30 & 119,3 & $-53,7$ & 22,9 & $-42,7$ & $-1,4$ & \\
\hline & $01 / 10-31 / 10$ & 31 & 41,6 & $-32,3$ & $-73,5$ & $-82,7$ & $-2,7$ & \\
\hline & 01/11-30/11 & 30 & 131,4 & 38,0 & $-11,2$ & $-180,7$ & $-6,0$ & \\
\hline & Total & 366 & 1316,0 & $-533,0$ & $-51,8$ & $-834,7$ & & 64 \\
\hline \multirow[t]{11}{*}{ Limão V. Catânia } & $01 / 12-25 / 03$ & 116 & 137,7 & 1,9 & $-62,6$ & $-202,2$ & $-1,7$ & \\
\hline & $26 / 03-15 / 04$ & 21 & 112,4 & 1,4 & 64,6 & $-49,3$ & $-2,3$ & \\
\hline & $16 / 04-15 / 05$ & 30 & 159,4 & $-71,7$ & $-7,8$ & $-95,5$ & $-3,2$ & \\
\hline & $16 / 05-10 / 06$ & 26 & 231,6 & $-118,7$ & 100,6 & $-12,3$ & $-0,5$ & \\
\hline & 11/06-30/06 & 20 & 115,8 & $-135,7$ & $-64,3$ & $-44,4$ & $-2,2$ & \\
\hline & $01 / 07-31 / 07$ & 31 & 82,2 & $-50,2$ & $-20,1$ & $-52,1$ & $-1,7$ & \\
\hline & 01/08-31/08 & 31 & 184,6 & $-125,5$ & 9,0 & $-50,1$ & $-1,6$ & \\
\hline & 01/09-30/09 & 30 & 119,3 & $-56,7$ & $-13,6$ & $-76,2$ & $-2,5$ & \\
\hline & $01 / 10-31 / 10$ & 31 & 41,6 & $-9,6$ & $-63,7$ & $-95,8$ & $-3,1$ & \\
\hline & $01 / 11-30 / 11$ & 30 & 131,4 & 16,5 & $-4,3$ & $-152,2$ & $-5,1$ & \\
\hline & Total & 366 & 1316,0 & $-548,2$ & $-62,2$ & $-830,0$ & & 44 \\
\hline \multirow[t]{11}{*}{ Limão Cravo } & $01 / 12-25 / 03$ & 116 & 137,7 & $-71,6$ & $-65,7$ & $-131,9$ & $-1,1$ & \\
\hline & $26 / 03-15 / 04$ & 21 & 112,4 & 1,1 & 56,3 & $-57,2$ & $-2,7$ & \\
\hline & $16 / 04-15 / 05$ & 30 & 159,4 & $-66,9$ & 3,8 & $-88,8$ & $-3,0$ & \\
\hline & 16/05-10/06 & 26 & 231,6 & $-103,5$ & 83,4 & $-44,8$ & $-1,7$ & \\
\hline & $11 / 06-30 / 06$ & 20 & 115,8 & $-102,2$ & $-61,4$ & $-75,0$ & $-3,8$ & \\
\hline & $01 / 07-31 / 07$ & 31 & 82,2 & $-48,6$ & $-12,1$ & $-45,8$ & $-1,5$ & \\
\hline & 01/08-31/08 & 31 & 184,6 & $-119,4$ & 12,4 & $-52,8$ & $-1,7$ & \\
\hline & 01/09-30/09 & 30 & 119,3 & $-71,0$ & $-4,0$ & $-52,3$ & $-1,7$ & \\
\hline & $01 / 10-31 / 10$ & 31 & 41,6 & $-36,9$ & $-68,2$ & $-72,8$ & $-2,3$ & \\
\hline & $01 / 11-30 / 11$ & 30 & 131,4 & $-3,6$ & $-7,9$ & $-135,6$ & $-4,5$ & \\
\hline & Total & 366 & 1316,0 & $-622,5$ & $-63,5$ & $-757,0$ & & 60 \\
\hline \multirow[t]{11}{*}{ Limão R. da Flórida } & $01 / 12-25 / 03$ & 116 & 137,7 & $-40,2$ & $-67,1$ & $-164,6$ & $-1,4$ & \\
\hline & $26 / 03-15 / 04$ & 21 & 112,4 & 0,5 & 37,4 & $-75,6$ & $-3,6$ & \\
\hline & $16 / 04-15 / 05$ & 30 & 159,4 & $-52,3$ & 5,5 & $-101,6$ & $-3,4$ & \\
\hline & $16 / 05-10 / 06$ & 26 & 231,6 & $-47,4$ & 93,8 & $-90,4$ & $-3,5$ & \\
\hline & $11 / 06-30 / 06$ & 20 & 115,8 & $-128,4$ & $-60,7$ & $-48,0$ & $-2,4$ & \\
\hline & 01/07-31/07 & 31 & 82,2 & $-42,6$ & $-21,3$ & $-60,9$ & $-2,0$ & \\
\hline & 01/08-31/08 & 31 & 184,6 & $-107,7$ & 21,8 & $-55,1$ & $-1,8$ & \\
\hline & 01/09-30/09 & 30 & 119,3 & $-68,4$ & $-7,3$ & $-58,2$ & $-1,9$ & \\
\hline & $01 / 10-31 / 10$ & 31 & 41,6 & $-26,3$ & $-57,9$ & $-73,2$ & $-2,4$ & \\
\hline & $01 / 11-30 / 11$ & 30 & 131,4 & 20,5 & $-8,0$ & $-159,9$ & $-5,3$ & \\
\hline & Total & 366 & 1316,0 & $-492,3$ & $-63,9$ & $-887,6$ & & 56 \\
\hline \multirow[t]{11}{*}{ Tangerina Cleópatra } & $01 / 12-25 / 03$ & 116 & 137,7 & $-46,2$ & $-50,7$ & $-142,2$ & $-1,2$ & \\
\hline & $26 / 03-15 / 04$ & 21 & 112,4 & 1,9 & 30,5 & $-83,8$ & $-4,0$ & \\
\hline & $16 / 04-15 / 05$ & 30 & 159,4 & $-1,9$ & $-0,5$ & $-158,0$ & $-5,3$ & \\
\hline & $16 / 05-10 / 06$ & 26 & 231,6 & $-57,3$ & 119,9 & $-54,4$ & $-2,1$ & \\
\hline & 11/06-30/06 & 20 & 115,8 & $-178,1$ & $-77,9$ & $-15,6$ & $-0,8$ & \\
\hline & $01 / 07-31 / 07$ & 31 & 82,2 & $-46,9$ & $-21,8$ & $-57,2$ & $-1,8$ & \\
\hline & 01/08-31/08 & 31 & 184,6 & $-112,2$ & 13,9 & $-58,5$ & $-1,9$ & \\
\hline & 01/09-30/09 & 30 & 119,3 & $-37,9$ & $-25,4$ & $-106,8$ & $-3,6$ & \\
\hline & $01 / 10-31 / 10$ & 31 & 41,6 & 12,3 & $-35,6$ & $-89,5$ & $-2,9$ & \\
\hline & $01 / 11-30 / 11$ & 30 & 131,4 & 44,0 & $-3,3$ & $-178,8$ & $-6,0$ & \\
\hline & Total & 366 & 1316,0 & $-422,1$ & $-51,0$ & $-944,9$ & & 36 \\
\hline
\end{tabular}

O primeiro fato a se destacar na Figura 1A comum a todos os porta-enxertos e relacionados à drenagem, diz respeito à existência de ascensão capilar no período que antecede a estação chuvosa, à exceção do Limão Volcameriano Palermo (1D) que apresenta, no entanto, taxa de drenagem muito baixa. Esta fase coincide com o final do período seco, quando as reservas de água no solo são baixas, e com o início da maturação dos frutos, estimulado pelas primeiras chuvas. No período imediatamente posterior, correspondente ao início da estação chuvosa (16/04 a 15/06) a drenagem interna se faz presente apesar da elevada taxa 
de evapotranspiração de todos os materiais, face à constância e ao volume das chuvas. Vale ressaltar, no entanto, que neste período a evapotranspiração da Tangerina Cleópatra já é muito elevada em relação aos outros porta-enxertos, restringindo ao máximo a taxa de drenagem.

Um segundo fato a se destacar pode ser observado na fase pós-período chuvoso, correspondente aos meses de outubro e novembro, nos quais as plantas se encontram em estágio de máxima atividade (fase de formação dos botões florais e início da frutificação). É possível verificar-se, em todos os porta-enxertos, forte redução das taxas de drenagem no mês de outubro e processo de ascensão capilar no mês de novembro. Nesta fase, diferentemente da que antecedeu ao período chuvoso, a ascensão capilar foi, provavelmente, originada das elevadas taxas de evapotranspiração na medida em que não houve redução sensível da precipitação pluvial nesses meses. Mais uma vez, vale ressaltar o comportamento da Tangerina Cleópatra, cujas taxas de evapotranspiração, mantidas altas desde o final do período chuvoso (mês de setembro) forçaram o processo de ascensão capilar, já no mês de outubro.

Na última coluna da Tabela 3 estão apresentados os índices EUA, que permitem comparar os porta-enxertos quanto à eficiência de absorção de água em quilograma de frutos produzidos por porta-enxerto, para cada metro cúbico de água absorvido. O baixo valor do índice EUA para a Tangerina Cleópatra confirma o resultado do balanço hídrico que atribui, a este porta-enxerto, as maiores taxas de evapotranspiração nos períodos de maior demanda hídrica da planta. Quanto aos outros materiais observa-se a existência de certa homogeneidade quanto à eficiência de uso da água do solo. Convém ressaltar, no entanto, que o Limão Cravo, por apresentar as menores taxas de evapotranspiração entre os três materiais, deve reagir de forma mais positiva, quanto ao uso da água no solo, em anos com déficits pluviométricos acentuados. Com base em levantamento feito pela FAO (Doorenbos \& Kassam, 1979) os índices relacionados à eficiência da água para a cultura do citros situam-se entre 2 e 5 , o que reafirma a baixa performance da Tangerina Cleópatra ao ecossistema avaliado, na medida em que este material apresenta o valor que mais se aproxima do limite mínimo de EUA estabelecido para esta cultura.

\section{CONCLUSÕES}

1. Na área estudada, a maior demanda hídrica da laranja Pêra (Citrus sinensis (L.) Osbeck) enxertada sobre Limão Volcameriano Palermo e Catânia (Citrus volkameriana Pasquale), Limão Cravo (Citrus limonia Osbeck), Limão Rugoso da Flórida (Citrus jambhiri Lush) e Tangerina Cleópatra (Citrus reshni
Hort. ex Tan) acontece nos meses de outubro e novembro. Demanda importante ocorre, também, no final do período seco, durante a fase de maturação dos frutos.

2. Com base na taxa de evapotranspiração apresentada pelos porta-enxertos nos estádios fenológicos de grande demanda hídrica, é possível concluir que a Tangerina Cleópatra é o porta-enxerto menos adaptado e o Limão Cravo o que apresenta as melhores características de adaptação na área estudada, quanto a esta característica.

\section{REFERÊNCIAS BIBLIOGRÁFICAS}

CASTLE, W.S.; TUCKER, D.R.H.; KREZDORN, A.H.; YOUTSEY, C.O. Rootstocks for Florida citrus: Rootstock selection the first step to success. Gainesville: University of Florida, Institute of Food and Agricultural Sciences, 1989. 48p.

DOORENBOS, J.; KASSAM, A.H. Effectos del agua sobre rendimiento del los cultivos. Roma: FAO, 1979.212p. Estudio FAO:Riego y Drenaje, 33.

EMPRESA BRASILEIRA DE PESQUISA AGROPECUÁRIA. Centro de Pesquisa Agropecuária dos Tabuleiros Costeiros. Plano Diretor do Centro de Pesquisa Agropecuária dos Tabuleiros Costeiros (CPATC). Brasília: EMBRAPA, SPI, 1994. 37p.

HILLEL, D. Solo e água: Fenômenos e princípios físicos. Porto Alegre: UFRGS, Departamento de Solos, 1970. 231p.

HILLEL, D. The field water balance and water use efficiency. In: HILLEL, D. (ed.) Optimizing the soil physical environment toward greater crop yields. New York: Academic Press, 1972. p.79-100.

LIBARDI, P.L. Dinâmica da água no solo. Piracicaba, 1995. 497p.

MECHLIA, N.B.; CARROLL, J.J. Agroclimatic modeling for simulation of phenology, yield and quality of crop production. I. Citrus response formulation. International Journal of Meteorology, v.33, n.1, p.36-51, 1989.

OLIVEIRA, J.B. de. Solos para citros. In: RODRIGUEZ, O.; VIÉGAS, J.; POMPEU JÚNIOR, J.; AMARO, A.S. (eds.) Citricultura brasileira, 2.ed. Campinas: Fundação Cargill, 1991. v.1, p.196-227.

ORTOLANI, A.A.; PEDRO JÚNIOR, M.J.; ALFONSI, R.R. Agroclimatologia e o cultivo dos citros. In: RODRIGUEZ, O.; VIÉGAS, J.; POMPEU JÚNIOR, J.; AMARO, A.S. (eds.) Citricultura brasileira, 2.ed. Campinas: Fundação Cargill, 1991. v.1, p.153-195.

REUTHER, W. Climate and citrus behavior. In: REUTHER, W. (ed.) The citrus industry. Berkeley: University of California, 1973. v.3, p.280-337, cap.9. 